\title{
Understanding investment policy choices for individual pension plans
}

Received (in revised form): 19th June, 2002

\section{John Hibbert}

graduated in economics and accounting and then operational research, and gained over 20 years experience in the life insurance, asset management and securities industries. Until 1990, John was responsible for portfolio strategy at Prudential. From 1991-95 he led the equity quantitative research team at NatWest Securities. In 1995 he co-founded Barrie \& Hibbert, an independent consultancy business based in Edinburgh servicing the savings industry, and DecisionsDecisions, a provider of on-line risk illustration software.

\section{Philip Mowbray}

graduated in mathematics and statistics and then operational research, and he has worked as a statistical research analyst on a large medical research study, and contributed to research journals in that field. Since joining Barrie \& Hibbert four years ago, he has worked on a wide range of projects as well as specialising in the development of Barrie \& Hibbert's interest rate modelling capability and DecisionsDecisions' financial models.

\begin{abstract}
This paper provides a first step to understanding the pensions 'lifestyle' problem and designing efficient solutions for savers. A stochastic simulation model is used to map out the benefits likely to be delivered from some conventional investment policies and switching policies. Benefits are measured in real and nominal terms and the distribution of final benefits is analysed as well as the variability of the built-up benefit.
\end{abstract}

Keywords: pension planning; risk; asset allocation; lifestyle; simulation; stochastic models

John Hibbert

Barrie \& Hibbert, 48 Melville Street, Edinburgh EH3 7HE, UK. Tel: +44 (0)131625 0206; Fax: +44 (0)131625 0215; e-mail:

john.hibbert@barrhibb.com

\section{Introduction}

In recent years individual defined contribution (DC) pension arrangements have gained increased acceptance with corporate sponsors. This should be no surprise. Unlike defined benefit pension plans, where the sponsor underwrites the benefits and faces potentially disruptive and costly variations in contribution rates, the contributions required to fund a DC arrangement are far more stable and predictable. The reason for this is that those risks which were underwritten by the sponsor within the defined benefit scheme have been passed to the individual saver in the DC scheme. As this paper illustrates, some of these risks can be mitigated by good scheme design while others cannot.

In principle, the pensions problem is easy to understand. Over their working lifetime an individual must set aside a sufficient proportion of earnings to provide an income (at the point they stop earning) for the rest of their life. Of course, anyone who has considered the problem for more than a moment will understand than it is far from easy to 'solve'. The problem is complicated partly because a pension plan should be structured to withstand all sorts of uncertain future environments, but also 
because there are no unique criteria which can be used to judge success. Like most long-term financial planning problems, we must jointly understand several properties of any strategy together in order to serve the best interests of savers. This paper presents a framework to analyse what the authors judge to be the most critical properties of a 'lifestyle' strategy. (By lifestyle we mean a pre-set investment policy which will vary asset mix at different ages in order to produce better results for a saver than a static investment policy). Use is made of a stochastic (Monte Carlo) simulation model to generate and present the information necessary to make informed judgements about the attractiveness of different investment policy choices.

\section{Some perspectives on the problem}

\section{Definitions}

The saver's problem is to accumulate sufficient assets over his working lifetime to fund a desired pension income from some future date when he ceases to earn. This date could be called 'retirement', but earnings might cease for other reasons. Any individual might suffer ill health or simply find himself redundant sometime before his planned retirement date. Under these circumstances, the saver might choose to draw an income from the accumulated fund immediately, or to defer withdrawal (say until his planned retirement date). Some individuals may choose to work only until they have accumulated sufficient savings to fund a certain level of pension income. If the saver gets lucky, this might be achieved at age 45; in other circumstances the target income might not be achieved until age 75 . For the sake of clarity here is some terminology to describe the various phases of the savings 'lifecycle':

- Savings Phase: will describe the period for which a saver actively contributes to a fund

- Deferral Phase: will describe a period during which a fund might accumulate without the addition of contributions before drawdown or annuity purchase

- Drawdown Phase: will describe a period over which the saver makes a series of withdrawals from the fund. There are various rules the saver might adopt to set the level of withdrawal

- Annuity Purchase Date: will describe the time when the saver exchanges an accumulated fund for an annuity contract.

\section{Two questions}

At the beginning of this lifetime of saving and spending an individual faces enormous uncertainty. Someone might ask: how will my earnings grow over time? How long will I earn for? What returns will be delivered on investments? How will accumulated investments translate into annuity income 20 or 30 years in the future?

It is important be more precise about what questions should be answered and what criteria might be used to judge success or failure. Suppose that this analysis is focused on a particular saver of a given age, contribution profile, initial earnings and accumulated savings. Consider two questions:

Question 1: What are the chances of achieving different levels of final benefit with a given investment policy?

It might be asked what 'final benefit' really means in this context. It may seem 
an odd fact that there is not a straightforward answer to this question. Some plausible definitions of 'final benefit' are:

- the annual income achieved from a conventional annuity, at the point the saver converts his fund to pension, expressed in nominal terms ie in the money of the date of conversion.

Note that this value will be sensitive to projected inflation over the savings horizon. If the inflation rate over the savings phase is high, it will probably increase the nominal value of the fund and the resulting annuity in money terms.

- the annual income achieved from a conventional annuity, at the point the saver converts his fund to pension, expressed in real terms, ie in terms of today's money.

This might avoid creating the illusion that high inflation over the savings horizon creates high benefits. However, if we focus on a conventional annuity there could still be a tendency to overstate the real value of benefits in a high-inflation world. This will happen because, although the real starting value of pension might be high, inflation will erode its real value in payment rapidly in a world of high inflation.

- the annual income achieved from an index-linked annuity, ${ }^{1}$ at the point the saver converts his fund to pension, expressed in real terms, ie in terms of today's money.

It is also worth emphasising that investment policy relates to the entire savings horizon. A good investment policy choice might involve holding different asset mixes at different times. Further, it could also require holding different asset mixes dependent on other properties of the plan.
Question 2: How much will the projected final benefit vary from year to year during the savings phase?

Rather than focusing on the final result of a savings plan, this question is concerned with possible variations in the projected benefit over time. This particular feature of the plan will be of most interest to savers close to retirement. Imagine a person with an accumulated fund of $\$ 100,000$, five years before a planned retirement at age 65. He asks a friendly actuary to assess the level of projected index-linked annuity which his fund would buy. $\mathrm{He}$ tells him that, given current interest rates, the fund should buy an annuity of $\mathcal{E}^{8,300}$ p.a. He reckons that he needs an income of at least $\mathcal{E} 10,000$ p.a. in retirement, so he sets about topping up the fund through additional contributions. In this situation, he will place a high value on predictability. In a scenario where he did choose to make a series of additional contributions, but subsequently found the realised benefit fell short of $£ 8,300$ p.a., he would probably be both surprised and disappointed. (This might happen, first, if his investments perform poorly over the five years to retirement; secondly, if index-linked yields fell significantly over the period; thirdly, a large change in the actuary's assumption for future mortality).

The second question relates to variations in projected benefits. Strategies which make the final benefit predictable, particularly as a pension plan nears maturity (when much of the earnings and contribution-related risks are behind us) will have considerable value. ${ }^{2}$

\section{The problem with the problem}

Our fundamental task is to understand how different investment policy choices affect the answers to the two questions. However, the discussion above suggests 
that this could be very complicated. The task requires understanding the interaction between the chosen investment policy, contribution profile and the market environment to see the impact on final outcomes and the year-on-year build-up of benefits. This is no trivial task. People might say that it is next to impossible. These people would be wrong. Analysts have developed different kinds of solutions to this sort of problem:

- historical back-testing (and then assuming that the future will be like the past)

- scenario analysis (deterministic simulation/sensitivity analysis)

- Monte Carlo (stochastic) simulation

- finding an analytical expression to calculate some variable of interest.

There are advantages and disadvantages to each of these approaches. The first three will now be considered briefly.

\section{Historical back-testing}

The idea of a back-test is to calculate how some proposed product or investment strategy would have performed if it had been used in the past. It is then assumed that the future will be somehow like the past period analysed. This sort of testing can be very useful, but it usually does not go far enough. There simply are not enough past data around to test many strategies, particularly those with a long planning horizon or those involving derivative instruments.

\section{Scenario analysis}

Scenario analysis involves setting out a series of alternative 'futures' and attaching probabilities to each of them 'by hand'. The probabilities and scenarios can be used to calculate average (probability-weighted) payoffs and measures of the spread (risk) around this average. For certain types of problem this is a very powerful and intuitive approach. However, in situations where we care about the path taken by prices or interest rates it simply is not practical. This happens because the path will affect the results and so a very large number of scenarios is needed. A solution is to use a computer (and a statistician) to generate the scenarios automatically.

\section{Monte Carlo (stochastic) simulation}

Monte Carlo simulation can be used in situations where we believe that we can say something sensible about the factors which affect some problem, but do not know what will happen when all of the factors are put together. Road traffic engineers have a pretty good idea of how cars and drivers behave (how quickly they brake and accelerate etc.). They know how roads are laid out and the sequences of traffic lights. But it is impossible to capture all of this in a mathematical equation which will predict how traffic will behave. The maths is too complicated. Does this mean that road traffic engineers cannot predict how traffic will behave when they fiddle with a traffic light sequence? Not at all. They use computer simulations. The simulations throw up most of the features of real traffic - bottlenecks, queues, sudden empty roads etc. They allow the engineer to see how changes in some part of the system will affect its overall behaviour.

For the problem this paper is concerned with, people think they know something about the behaviour of capital markets, earnings and price inflation and likely contribution rates. Monte Carlo simulation can be used to understand what level of pension benefits might emerge in the hypothetical financial environment. Various characteristics can 
be mapped out by using a computer to generate many different capital market environments. In each simulated market future a path is calculated for interest rates and the pension fund. By keeping a record of each simulation result it is possible to create an estimate of the probability of different outcomes by seeing how often they are observed in the overall simulation. The simulation is expected to throw up some pictures which look like the past. Further, there may be some other possible scenarios which one can expect to see in the simulation test-tube, but which have never been observed. All being well, it will confirm the intuition for the possible behaviour of the pension plan. On the other hand, simulation may flush out some possibilities which have not even been considered. It could be that intuition was not quite as good as had been believed. And, like any other piece of analysis, it is only as good as the assumptions put into it. ${ }^{3}$ We will now set out the characteristics of a hypothetical pensions arrangement.

\section{How the simulation model works}

Whenever a financial model is used, it is necessary to strike a balance between the complexity required to capture important features of a problem and the simplicity which is desirable if we are to succeed in explaining the model. Customers have limited time and less patience, so it is important to make models as simple as possible. Some aspects of the model used to compile this paper are quite complicated. In this section the high-level assumptions used to drive the model are presented.

A case study will be presented to help illustrate the analysis. It begins by making some assumptions about a notional saver and the behaviour of the financial markets in which he invests.

\section{Asset returns and inflation simulation}

In this section an overview is provided of the asset and inflation simulation model. The technical aspects of the model and the justification for parameters are described elsewhere. ${ }^{4}$

For the purposes of analysis, a number of potential sources of uncertainty are of interest. In particular, over very long horizons (of 25 years and more), plausible paths must be generated for the real yield curve, the nominal yield curve and the inflation rate. This is desirable because, at each future point in any simulation trial, real and conventional annuities must be valued as well as index-linked and conventional coupon bonds. To achieve this, a complete specification is needed for real and nominal spot rate curves at each point in time.

\section{Interest rate simulation}

For the purposes of this simulation, the spot rate of interest $\mathrm{t}^{5}$ at any time $t$ for a zero-coupon bond maturing at time $T$ is assumed to comprise two components:

- a real spot rate of interest for the period from time $t$ to time $T$. This is calculated using a two-factor version of the Hull-White yield curve model. - inflation expectations from time $t$ to time $T$. This term structure of inflation expectations is also modelled using a two-factor Hull-White model.

Thus, the spot rate of interest for any maturity is the sum of four underlying stochastic processes. The shocks to these stochastic processes are normal and jointly distributed with the excess returns ${ }^{6}$ on equity assets. In summary, long-term bond yields can change as a result of changing real interest rates, or because of changes in inflation expectations or because the inflation risk 


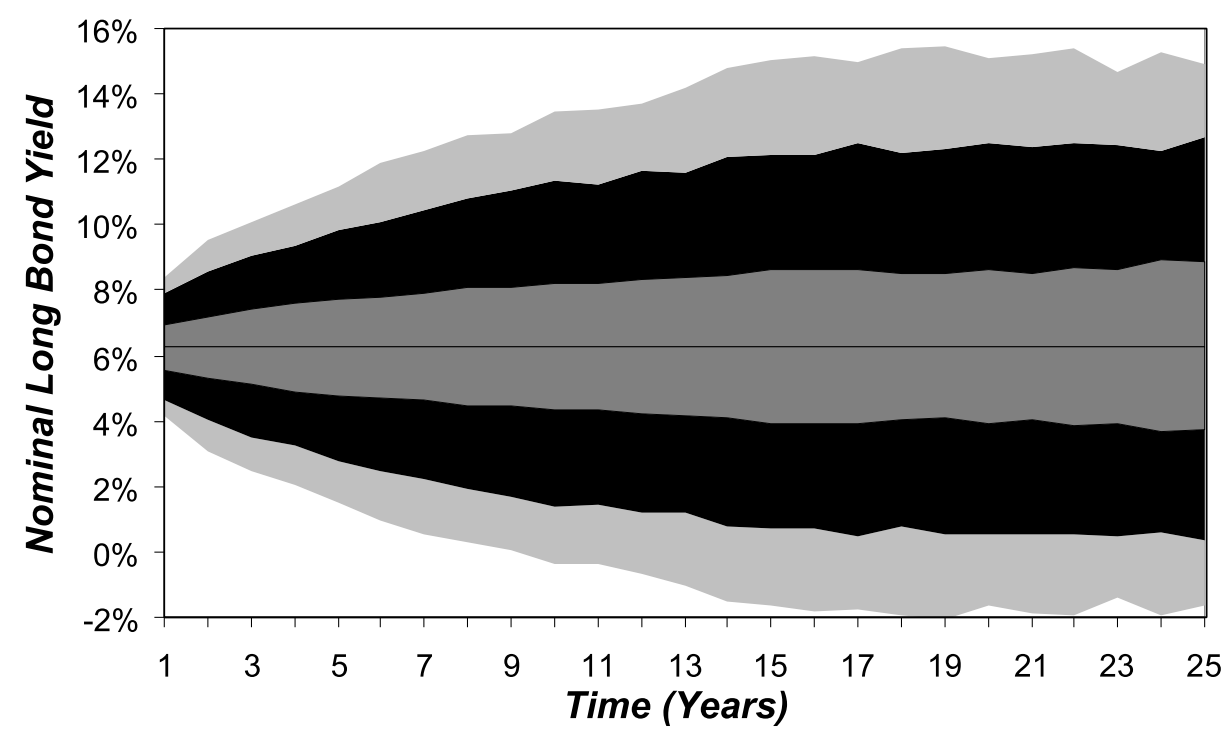

Figure 1: Simulated distribution of 20 -year spot rate of interest

premium changes (or some combination of all of these factors). Figure 1 shows the distribution of results for 1,000 simulations for the 20-year spot rate of interest. The middle band of grey shows the inter-quartile range of results. The black bands span the 5th to 95th percentile points in the simulation results. Finally, the lightest shaded area covers the 1st to the 99th percentile points. If we use the model (and a particular parameter set) to simulate scenarios for the financial environment out 25 years to 2027 , then there will be roughly a 1 in 100 chance of experiencing long bond yields in excess of 15 per cent at year 25.

Some people might say that the spread of long-term yields shown in Figure 1 is too narrow. Others will tell us that the distribution looks too wide. In practice, one of the main attractions of using a model is that the model parameters can be adjusted to reflect these differences in views. It could be the case that the overall conclusions do not change at all under different assumptions about the future distribution of long-term yields - the model can be used to test this proposition too. At any rate, Figure 1 shows one possible profile for a particular set of model parameters. The authors believe it is a reasonable starting point for their analysis.

Note that the model does allow the possibility of negative nominal interest rates. This property of the model would be easy to remove if we were only concerned with the nominal rate. It arises because we have chosen here to manufacture nominal rates from a real component (which can be negative) and inflation expectations (which can also be negative). In practice - for the purpose of the analysis presented here - we do not believe that this is a serious shortcoming.

\section{Equity markets}

Mercifully, equity market returns can be mimicked with a relatively simple model. Equity excess returns are assumed to be normally distributed with the standard deviation shown in Table 1.

Table 1 also shows the standard 
Table 1: Summary of asset class returns

\begin{tabular}{lll}
\hline Asset class & Log return (\% pa) & Standard deviation $(\%$ pa) \\
\hline UK equities & 9.0 & 16 \\
Long-dated bonds & 6.0 & 9 \\
Index-linked bonds & 5.75 & 7.5 \\
Cash & 5 & 3 \\
Inflation & 2.5 & 2.1 \\
\hline
\end{tabular}

Table 2: Simulate correlation between asset classes

\begin{tabular}{lllll}
\hline & Equities & Long-dated bonds & Index-linked bonds & cash \\
\hline Equities & 1.0 & & & \\
Long-dated bonds & 0.3 & 1.0 & 1.0 & \\
Index-linked bonds & 0.3 & 0.8 & 0.4 & 1.0 \\
Cash & 0.2 & 0.3 & \\
\hline
\end{tabular}

deviation of simulated returns for long-dated conventional and index-linked default-free bonds, cash and inflation. These figures are all broadly consistent with the empirical behaviour of the markets.

Table 2 shows the correlation of returns generated from the stochastic model. Like the volatility properties of the model, the simulated correlations are broadly consistent with the empirical behaviour of the financial markets.

\section{The pensions liability}

Next, let us define the liability in the notional pension plan. If we adopt the convenient assumption that the saver expects to retire at a certain age and to buy an income for the remainder of his lifespan at that age, it is possible to calculate the value of this deferred annuity at any point in time so long as there is a complete picture of the term structure of interest rates, together with the corresponding set of mortality rates (or survival probabilities). Since the model will simulate spot interest rates over each simulation, it is also possible to calculate the market value of the liability each year in the simulation. Further, because we simulate the real and nominal spot rate, we can calculate the price of annuities expressed in either real or nominal terms. Finally, in addition to calculating the price of a deferred annuity, it is also possible to calculate the price of an immediate real or nominal annuity, at any point in the simulation. Note that the changes in the price of the liability from year to year are sometimes referred to as 'liability returns'.

\section{Mortality}

Although it is convenient to assume that future mortality rates are known, in practice actuaries have had a rather poor record in forecasting changes in mortality rates (because it is very difficult). This source of risk is captured in the model by allowing mortality rates to vary away from initial expectations according to a stochastic factor.

\section{Salary inflation}

For most savers, there is considerable uncertainty about their future earnings. This uncertainty will expand as we extend the horizon for the analysis. It is important to understand that this earnings 
Table 3: Summary of investment policy choices

\begin{tabular}{lll}
\hline Investment policy & Business asset mix & Switching \\
\hline A & $100 \%$ Cash & None \\
B & $100 \%$ Equities & None \\
C & $100 \%$ Long Bonds & None \\
D & $100 \%$ Index-Linked Bonds & None \\
E & $100 \%$ Equities & Switch Bonds over 5 years \\
F & $100 \%$ Equities & Switch Bonds over 10 years \\
G & $100 \%$ Equities & Switch Bonds over 15 years \\
\hline
\end{tabular}

The switching strategies involve the switch of a fixed proportion of the equity fund into a 15 -year $5 \%$ coupon bond over the relevant period.

uncertainty affects the analysis in two ways. First, it might affect the contributions paid into the fund. If an individual targets a particular percentage contribution rate (rather than a money contribution level in order to fund a desired level of income in retirement), then contributions will rise or fall in line with earnings. Secondly, if final benefits are expressed as a percentage of final earnings then they will enter the analysis in a significant way.

Earnings uncertainty is important, but it is not an important part of the analysis in this paper. For the purposes of this modelling exercise we have assumed a fixed rate of earnings growth of 2.5 per cent p.a. in excess of inflation.

\section{Investment policy}

There is a wide choice of possible fund types and an infinite array of possible investment policy choices for savers. Initially, the analysis will be limited to some conventional strategies. Consider Table 3. It shows the seven strategies which will be analysed later.

\section{Simulation step-by-step}

So, how can all this be put together? First, the potential behaviour of the pension plan will be simulated over a long-term horizon. A large number of simulations are normally made. There will normally be 500 simulation trials. Essentially, each simulation trial works by moving through a simulated future year-by-year for investment returns, accumulating the pension fund and recording the values of variables of interest until the horizon is reached. How this works can be considered one step at a time:

Step 1: New contributions. Calculate the contribution for the current year which will depend on current earnings and the assumed contribution rate for the current age of the saver. Contributions are paid on 1st January each year.

Step 2: Sample the investment returns and inflation for the year.

Simulate the new position of the index-linked and conventional yield curves.

Step 3: Update the pension fund. The investment return is applied to the fund.

Step 4: Update the mortality rates. The probabilities in the mortality table are adjusted to account for changes in mortality rates.

Step 5: Make a record of variables of interest. Record the value of the accumulated fund, earnings, inflation as well as the market value of immediate and deferred annuities (conventional and index-linked). 


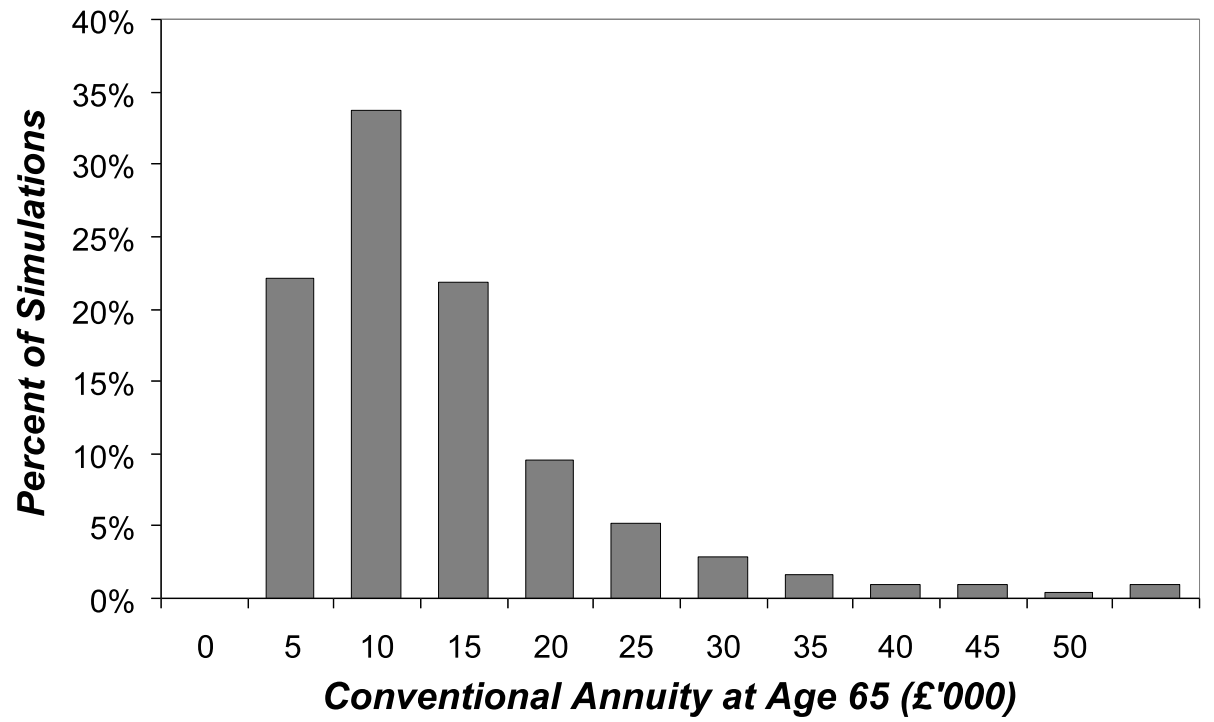

Figure 2: Distribution of achieved conventional annuity at age 65 (100\% cash investment)

Step 6: If the simulation horizon is reached then go to Step 6. Otherwise, wind the clock on another year and go back to Step 1.

Step 7: If the required number of simulation trials is complete, then stop. Otherwise, reset the clock to time zero, re-set all variables to their initial values and go back to Step 1.

\section{Model applications}

It is useful to put all of these ideas together to analyse some specific problems. In each case many possible paths will be generated for future investment returns and interest rates so the potential joint behaviour of assets and liabilities can be analysed.

Table 4: Mode parameters

\begin{tabular}{ll}
\hline & Value \\
\hline Initial earning (£p.a.) & 15,000 \\
Current age (Years) & 40 \\
Planned retirement age (Years) & 65 \\
Accumulated savings (£) & nil \\
Contribution rate (\%) & 8.0 \\
\hline
\end{tabular}

\section{A long-horizon problem (at age 40)}

First, consider an individual at age 40, called Mr Sprightly. He has current earnings of $\mathcal{£} 15,000$ p.a., no accumulated savings and plans to contribute 8 per cent of his earnings over his working lifetime. He intends to retire at age 65 . Suppose that it is also assumed, at least to begin with, that he invests 100 per cent of his contributions in cash. What sort of final benefits should Mr Sprightly expect to receive?

\section{Conventional annuity}

The simulation model has been used to generate 1,000 25-year paths for asset prices, inflation and interest rates. In each simulation it is possible to calculate the final benefit achievable with the fund. Figure 2 shows a frequency distribution for the simulated conventional annuity achieved by Mr Sprightly after 25 years. It can be seen that the distribution is very wide; around 30 per cent of simulations produce an annuity of $\mathcal{E}^{5-10,000}$ p.a. In approximately 2 per cent of the simulations the annuity exceeds $\mathcal{2} 45,000$ 


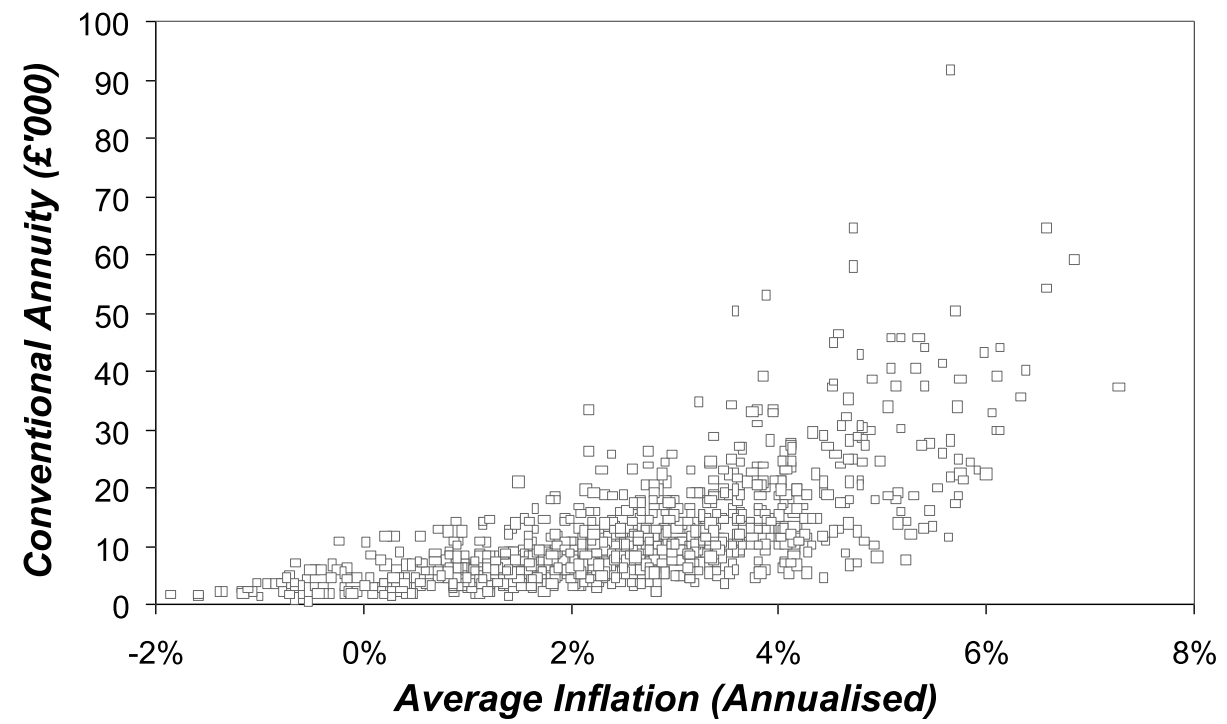

Figure 3: Achieved conventional annuity at age 65 vs average inflation (100\% cash investment)

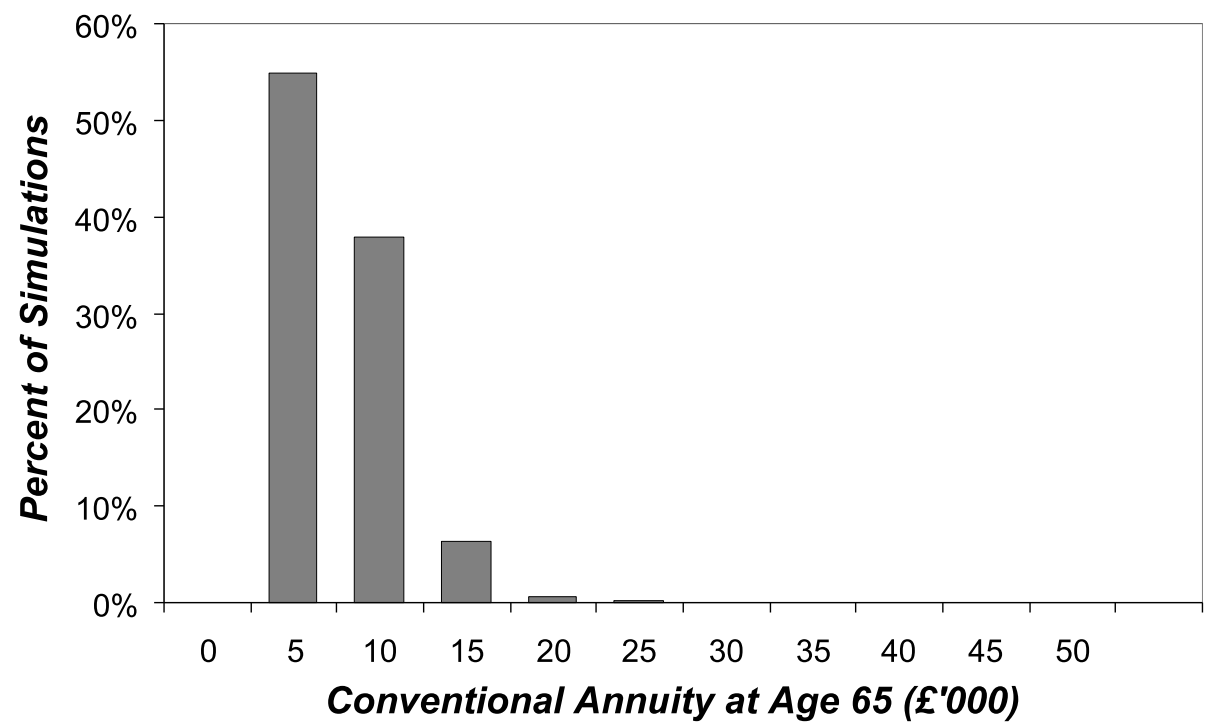

Figure 4: Distribution of achieved conventional annuity at age 65 (100\% cash investment)

p.a. However, it is important to understand that the huge variations in benefits are largely as a result of the different simulated inflation experiences.

Figure 3 plots the conventional annuity achieved in each simulation trial against the average rate of inflation generated for that simulation. It is clear that the highest conventional annuity rates were produced in simulated environments of very high average inflation. Of course, if these results are expressed in today's money they look far less attractive.

Figure 4 shows the same results, but the annuity is converted into current 


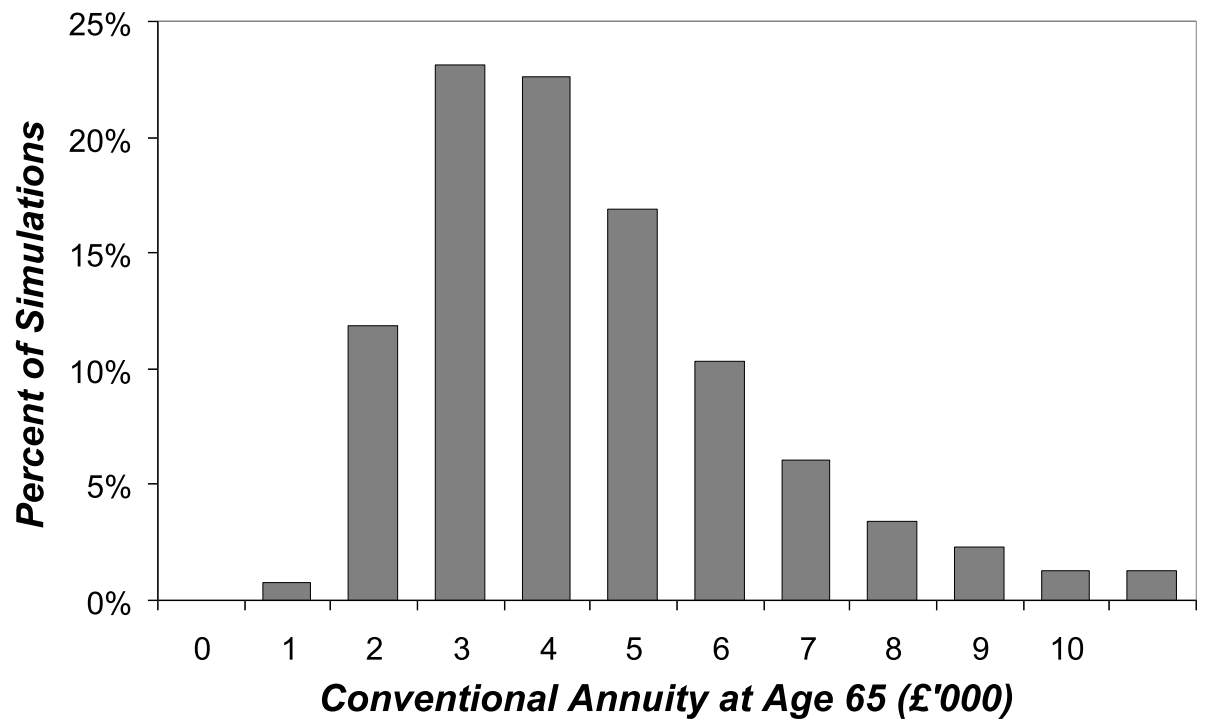

Figure 5: Distribution of index-linked annuity at age 65 (100\% cash) (current purchasing power)

purchasing power by dividing by the relative price level ${ }^{7}$ at year 25 . The overall distribution is now much narrower. It is clear that, in terms of today's money, the chance of the annuity falling between $£ 5,000$ p.a. and $£ 10,000$ p.a. is around 37 per cent.

\section{Index-linked annuity}

Suppose that we calculate the index-linked benefit achievable under each simulation and adjust this by the relative price level. The idea here is to remove the illusory effect of inflation completely from the analysis. In this case, the profile mapped out under Figure 5 would be seen. Again, this is narrower since short-term real yields on cash and on index-linked securities required to fund an index-linked liability are projected to be fairly stable (at least by comparison to nominal yields and to the inflation rate itself).

Figure 5 shows that, for an investor who invests in cash, there is around a 75 per cent probability of the fund delivering a real income of $£ 5,000$ p.a. or less. The chance of the real income exceeding $\mathcal{E}^{7}, 000$ p.a. is a little more than 5 per cent (one-in-20).

\section{Some investment policy comparisons}

So much for cash. Consider now the other investment policy choices set out in Table 3. How do the profiles shown above change if we vary investment policy? Figure 6 shows spreads of simulated results for the conventional annuity rate for the seven investment policies. Policy A (100 per cent cash) is plotted on the left-hand side of the figure with various percentile points shown for simulated outcomes. This is just another way of displaying the information plotted in Figure 2. The spreads between 25th and 50th percentile are shaded in dark grey (covering half the simulated outcomes). Another 40 per cent of the simulated outcomes are shaded in solid black within the 5th-25th and 75th-95th percentile ranges. The light grey areas show the 1 st -5 th and 95th-99th 


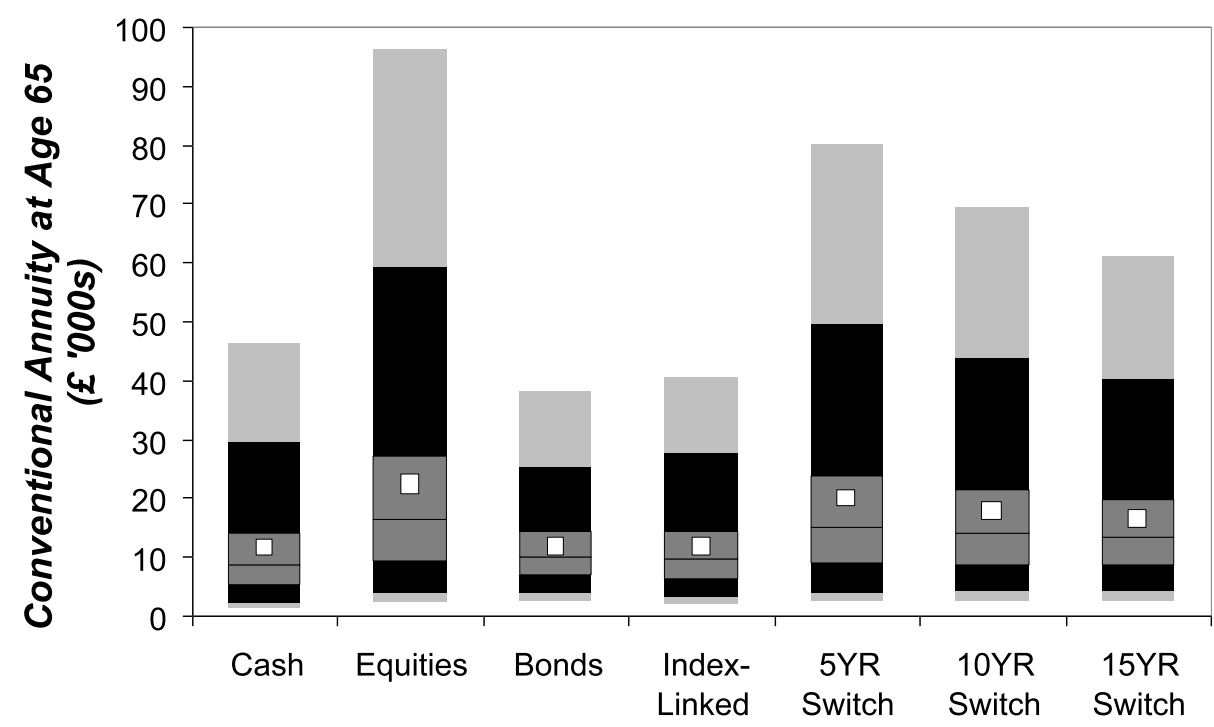

Figure 6: Distribution of conventional annuity at age 65

percentiles of results. The average outcome is plotted with a solid white box.

Figure 6 provides a clear demonstration of why equity investment is so attractive to savers with very long investment horizons. It can be seen that equities deliver the widest distribution of outcomes. But does this mean that they are the most risky investment? Looking at the position of the 95th percentile outcomes for the various policy choices, it might be argued that equity investment incurs lower risk than the cash or bond policies. The 95th percentile outcome is higher for equities than for cash or either of the bond categories. It can be seen that the probability of an equity strategy producing an annuity of $£ 10,000$ p.a. or less is much lower for equities than for the non-equity strategies.

Alternatively, the payoff could be expressed in terms of a real index-linked annuity measured in today's money (this is called 'current purchasing power' or CPP). For the reasons set out above, the conventional annuity and real conventional annuity are judged to be misleading at very long horizons. Policy B (100 per cent equities) has a dramatic impact on the distribution of real final benefits. Equities are assumed to deliver a rate of return some 3.5 per cent p.a. in excess of cash, so it should not be surprising that the average outcome is far higher than for the cash policy. Figure 7 shows that a policy of investing in index-linked bonds produces the narrowest range of outcomes, but an average outcome which is similar to cash. The switching strategies all reduce the average outcome and the spread of outcomes, although not in a dramatic way.

What is not apparent from this exhibit is that cash does outperform equities in a significant number of the simulations. This happens in around 10 per cent of the simulations. A scatter plot of the nominal fund values at year 25 is plotted in Figure 8. (Anyone finding the frequency of cash outperformance implausibly high might prefer to tweak up the assumed equity risk premium in the analysis. Alternatively, they might 


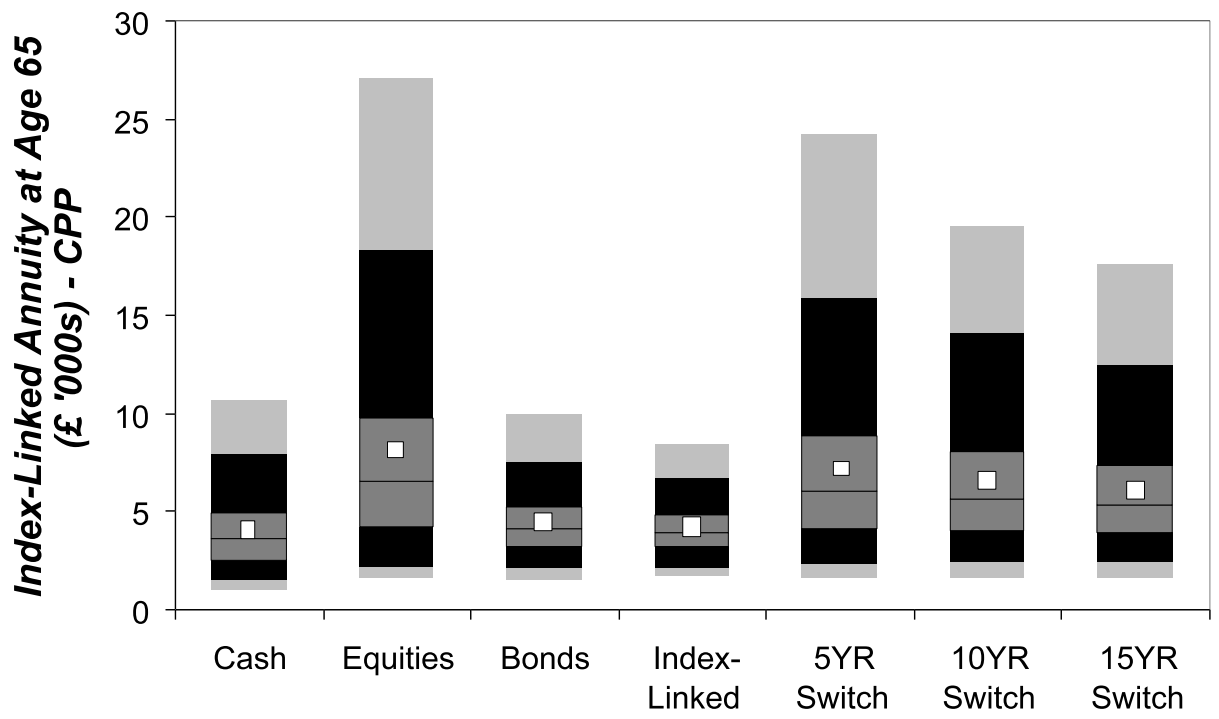

Figure 7: Distribution of index-linked annuity at age 65 (current purchasing power)

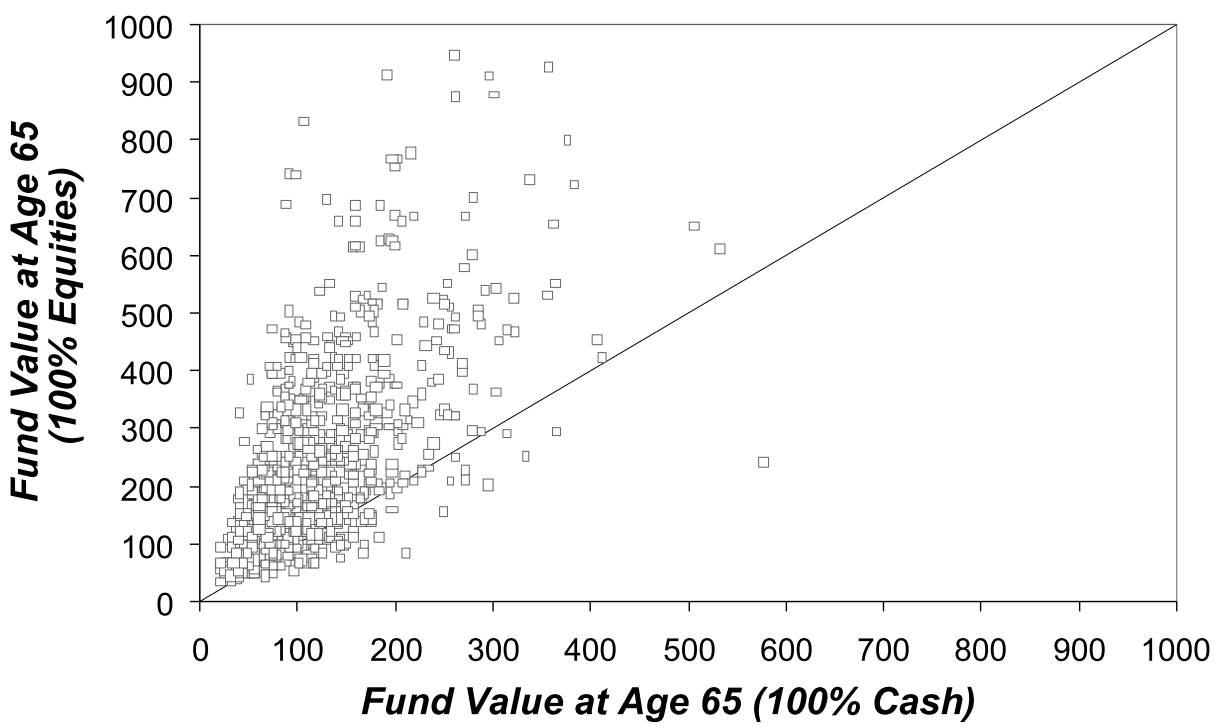

Figure 8: Simulated pension fund values at year 65 (100\% cash v. $100 \%$ equities)

review some of the very long-term performance data for equity assets and cash investments).

\section{The time factor}

The distributions shown in Figure 7 can be considered as a slice through probability distributions for the final benefit which could be drawn at any age within the savings phase. If we wound the clock back ten years and calculated the deferred index-linked annuity ${ }^{8}$ achievable at that time, a similar (but lower) profile could be drawn for the projected benefit. 


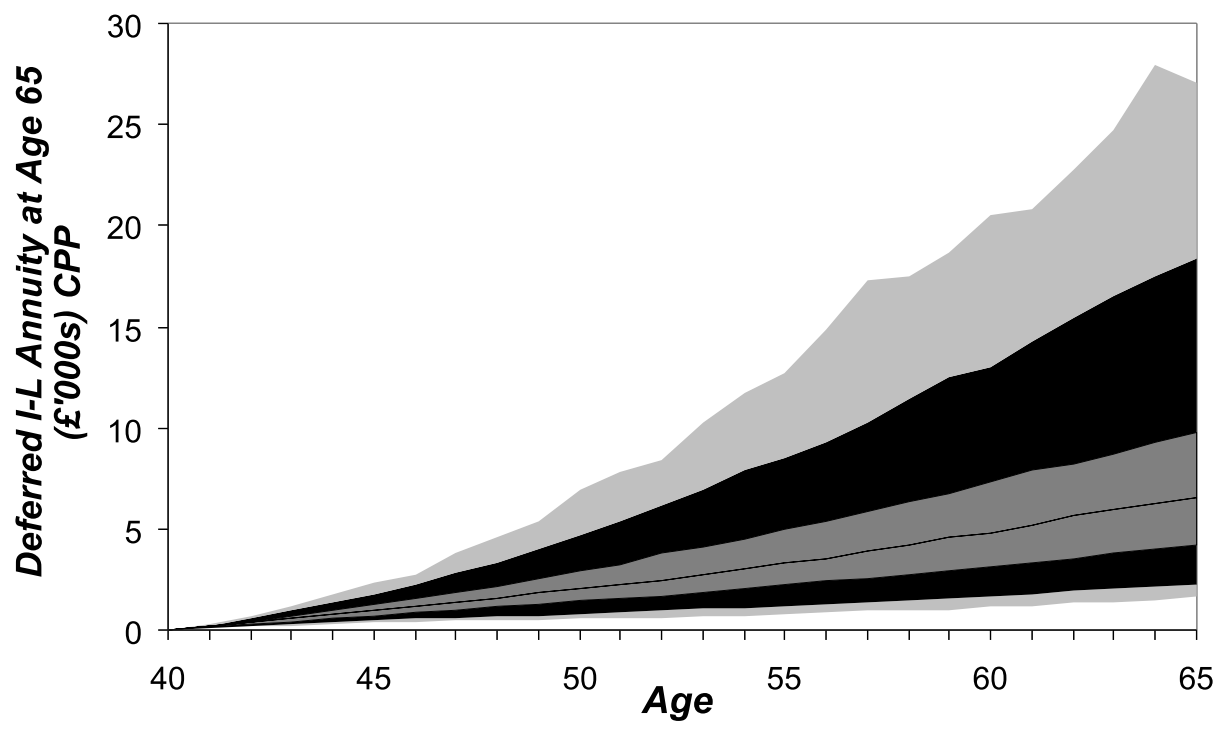

Figure 9: Distribution of deferred index-linked annuity (100\% equities) (current purchasing power)

Consider Figure 9. It shows the build-up of deferred index-linked benefit for the 100 per cent equity policy over the full 25-year savings period. Notice how the final spread on the right-hand side of the figure matches the spread for the equity policy shown in Figure 7. Remember that this shows the distribution for the deferred benefit at each point in the savings phase. In other words, if the saver were to stop contributing at any point, and buy an index-linked annuity which commences payment at age 65 , the figure shows the distribution of this benefit.

However, suppose the saver wanted to understand the accumulation of 'immediate' benefits (ie the annuity which could be bought with the fund which begins payment immediately). This might be appropriate if the saver were concerned with the risk of redundancy and needed to understand the real income he might achieve from the point of redundancy. Figure 10 plots this profile.

It can be seen that the final spread matches Figure 9, but as the clock is wound back over the saver's lifetime, the immediate benefits are projected to be much lower than the deferred benefits. This should not be a surprise because when the annuity is bought early there are two factors at work which will reduce the level of annuity income. First, we lose the potential benefit of future investment returns on the fund. Secondly, the annuity must cover a longer period of time. For example, at year ten (when the saver is age 50), Figure 9 tells us that there is 50 per cent probability that the accumulated fund will buy an index-linked income of $£ 2,370$ p.a. or more from age 65 . On the other hand, if the saver buys an immediate index-linked income annuity at age 50, which will run for an additional 15 years to age 65 , the equivalent median income is only 6955 p.a. (Figure 10).

When assessing the impact of redundancy risks on savers, it is important to think in terms of this last measure of the fund benefit - the immediate index-linked annuity because many redundant savers will be 


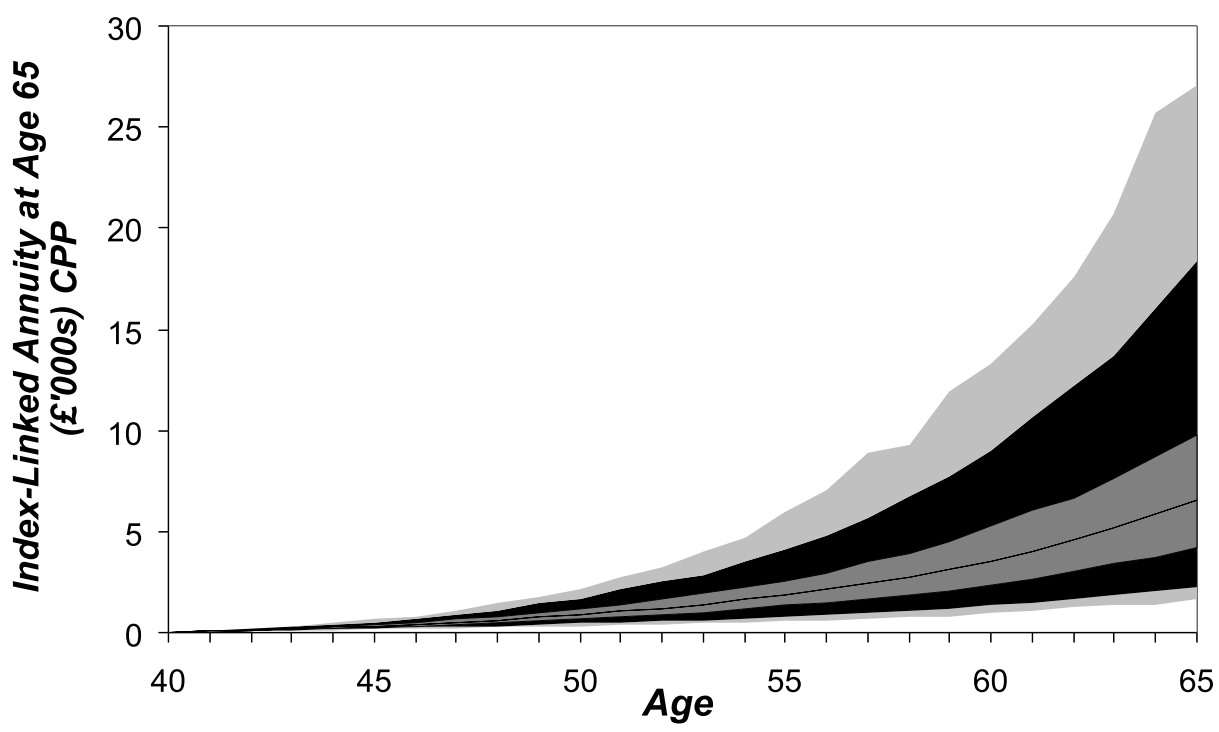

Figure 10: Distribution of immediate index-linked annuity (100\% equities) (current purchasing power)

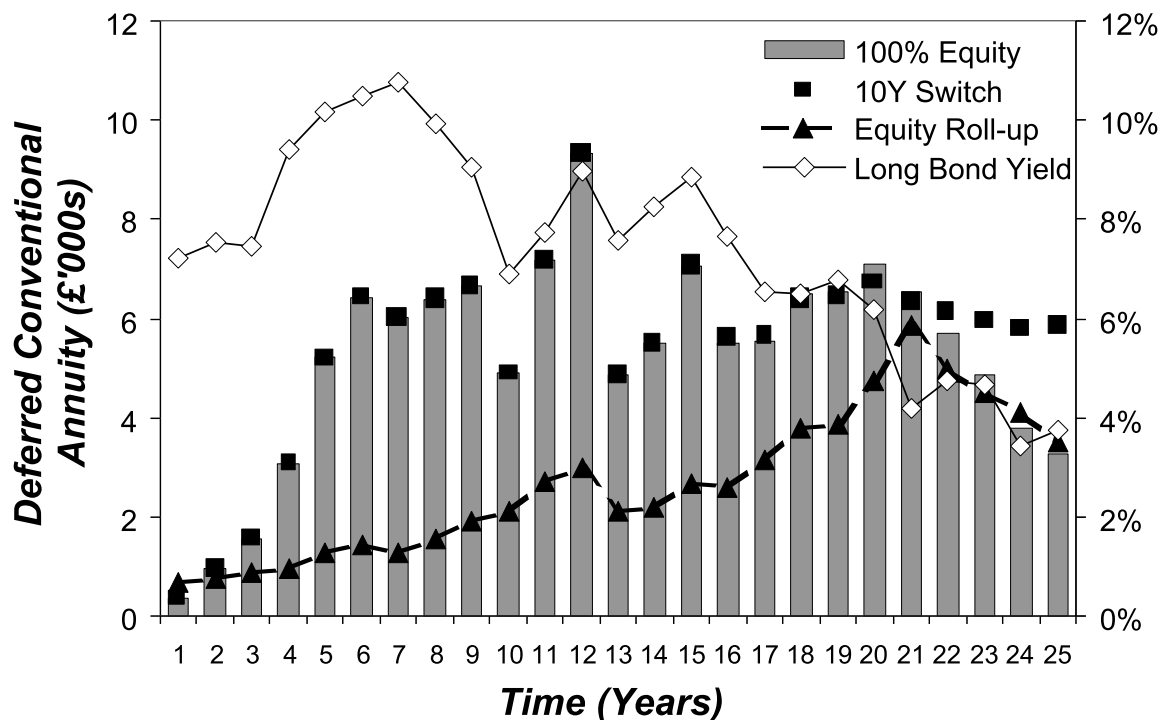

Figure 11: The benefit of switching - sample individual simulation

forced to fall back on this source of income.

\section{'Question 2' and benefit surprises}

Remember the second fundamental question asked: 'How will the projected final benefit vary from year to year during the savings phase?' The question reflects a need to understand the scope for surprising changes in the projected final benefit. These surprises occur when there are sharp movements in the value of investments or interest rates close to retirement.

Figure 11 shows one example of a 


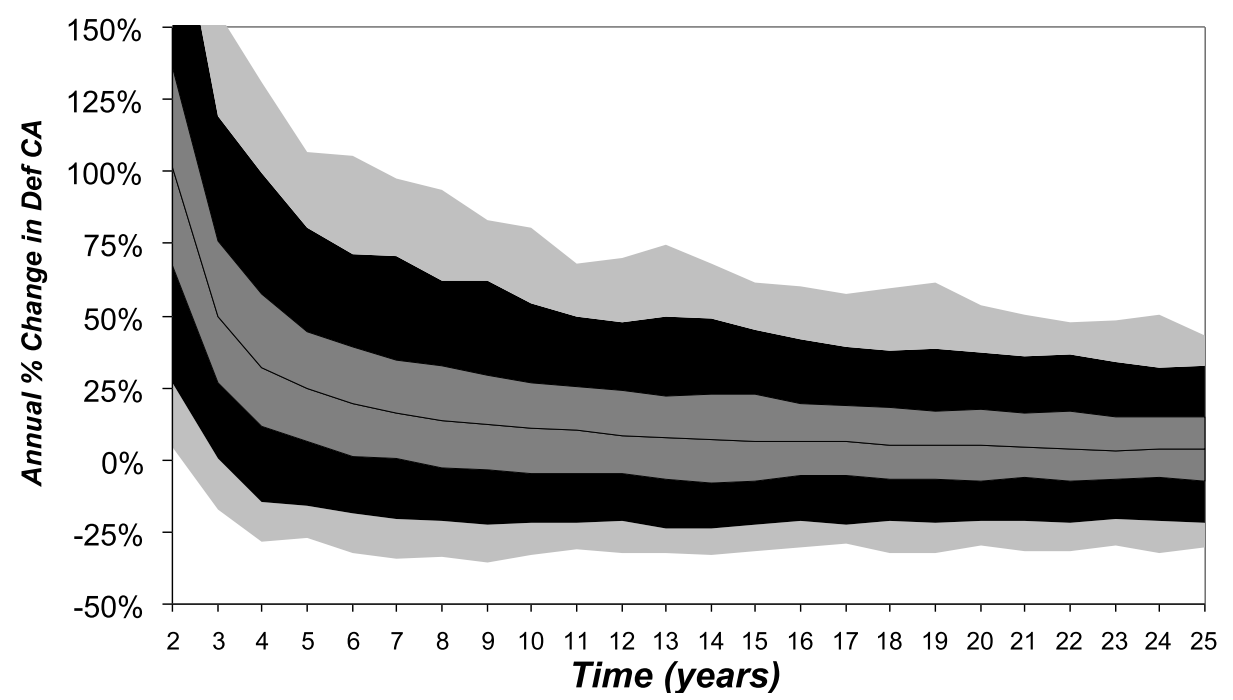

Figure 12: Distribution of year-on-year change in deferred conventional annuity (100\% equities)

simulation where the benefits from an equity policy and a ten-year switch to bonds produce dramatically different results. Here is a simulation where $\mathrm{Mr}$ Sprightly is hit by falling equity prices and falling bond yields in the run up to his annuity purchase. The tinted bars and solid boxes show the deferred conventional annuity which his accumulated fund will buy for an equity policy and equities together with a 'lifestyle' switch to bonds over the last ten years before retirement. You can see how the benefit builds up over time so that, by year 19 (age 59), the fund would buy an annuity of just less than £,12,000 p.a. (deferred for six years). From year 19 long bond yields fall from 8 per cent to 4.5 per cent over a six-year period and equity returns are negative. For the equity policy this double stroke of bad fortune reduces the annuity by 50 per cent to just under $£ 6,000$ p.a. For the lifestyle ten-year switch to bonds, the reduction is far more modest because of the heavy bond exposure. The final annuity is a little less than $\mathcal{E}_{11,000}$ p.a.

Figure 11 provides a neat illustration of the risk of mis-matching the bond-like annuity liability with an equity portfolio. Let us now analyse this risk in more detail.

Figure 12 provides some further insight into Question 2. It shows the range of projected benefit changes each year. Note that here the benefit is defined as the deferred conventional annuity and the investment policy is assumed to be 100 per cent equities. We have plotted the distribution of the year-on-year changes in projected benefits each year over Mr Sprightly's savings horizon. You can see that where the change is close to 0 per cent, this just shows that the projected benefit from year to year is pretty stable.

It is clear from Figure 12 that the equity policy exposes the saver to the chance of some significant benefit surprises. For example, it can be seen that, at year 15, when Sprightly is aged 55 , there is approximately a 5 per cent probability of the deferred benefit falling 25 per cent or more in a single year. Note that the overall profile takes on its unusual shape because, in the early years of the savings plan, new contributions 
are large relative to the accumulated fund so that the change in the projected benefit (from the accumulated fund) is likely to be large and positive.

In order to develop the analysis of benefit surprises, we will now turn to a short-horizon problem and analyse the problem from the perspective of a rather older saver with accumulated savings.

\section{The short-horizon problem (at age 55)}

Consider an individual at age 55 who plans to buy an annuity at age 65 , called Mr Gently. He has accumulated savings of $\mathcal{f} 50,000$. It is assumed (for the sake of simplicity) that he plans no further contributions into the pension plan.

\section{Conventional annuity}

First, consider the basic investment policies in order to understand the profile of conventional annuities projected at age 65 (after ten years). These profiles are plotted in Figure 13. The overall shape of the results looks similar to Figure 6 with the equity policy creating the best average benefits, but at the cost of the greatest variation.

However, it is striking that the 100 per cent bond policy now produces a fairly predictable outcome (at least when the benefit is measured in terms of a conventional annuity). Around 50 per cent of the simulated outcomes fall within a range of $£ 1,100$ p.a. compared to an equivalent 'inter-quartile' range of nearly $£ 8,000$ p.a. for the equity policy. It can also be calculated that Mr Gently

Table 5: Mode parameters

\begin{tabular}{ll}
\hline & Value \\
\hline Initial earning (£p.a.) & $\mathrm{n} / \mathrm{a}$ \\
Current age (Years) & 55 \\
Planned retirement age (Years) & 65 \\
Accumulated savings (£) & 50,000 \\
Contribution rate (\%) & 0.0 \\
\hline
\end{tabular}

could choose to buy a deferred annuity immediately and this would generate a known income of approximately $£ 8,000$ p.a. (beginning at year 10). This deferred annuity would be expected to behave like a bond because it is just a stream of more or less fixed payments. It should not be surprising that a bond investment proves to be a fairly close substitute.

\section{Index-linked annuity}

If the benefits from the seven strategies are now plotted in terms of an inflation-protected annuity, a similar picture occurs again, but with some notable differences to the analysis of conventional annuities. First, notice that when the benefits are expressed in real pounds the inter-quartile range for the equity policy narrows. In terms of today's money, half the outcomes for an equity policy fall within a range of approximately $\mathcal{E}^{2}, 000$ p.a. Notice also that the range of results for the cash policy is much narrower. This happens because, in this model, cash produces a variable real return in addition to the rate of inflation. The nominal return over the ten-year period on cash will depend on both real interest rates and delivered inflation. By contrast, the real return on cash (which determines the real benefit) will not be affected directly by the actual inflation experience.

Another interesting aspect of the analysis is the comparison between the bond and index-linked investment policies. In Figure 13, where the benefit is defined in money terms, conventional bonds produce a more predictable outcome than index-linked. This is because index-linked bonds mis-match the inflation risk in a conventional annuity. Compare this with Figure 14. Here, index-linked bonds deliver a more predictable outcome than conventional bonds. In a world of index-linked 


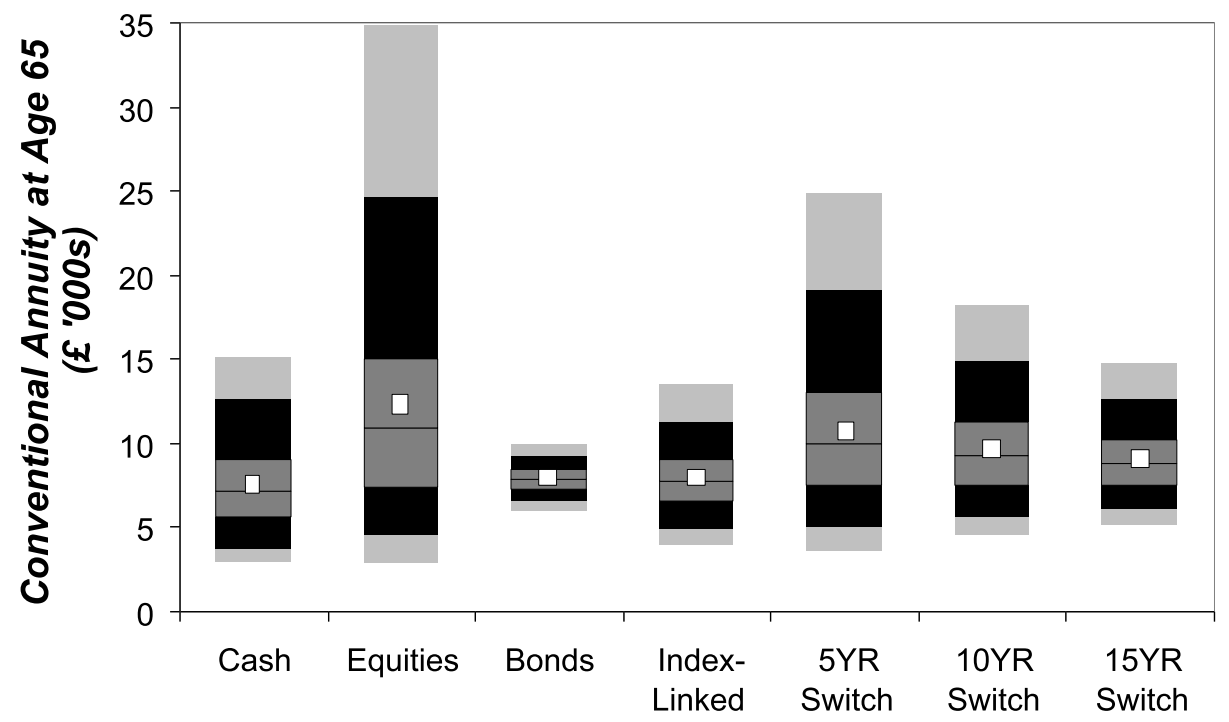

Figure 13: Distribution of conventional annuity at age 65 (current purchasing power)

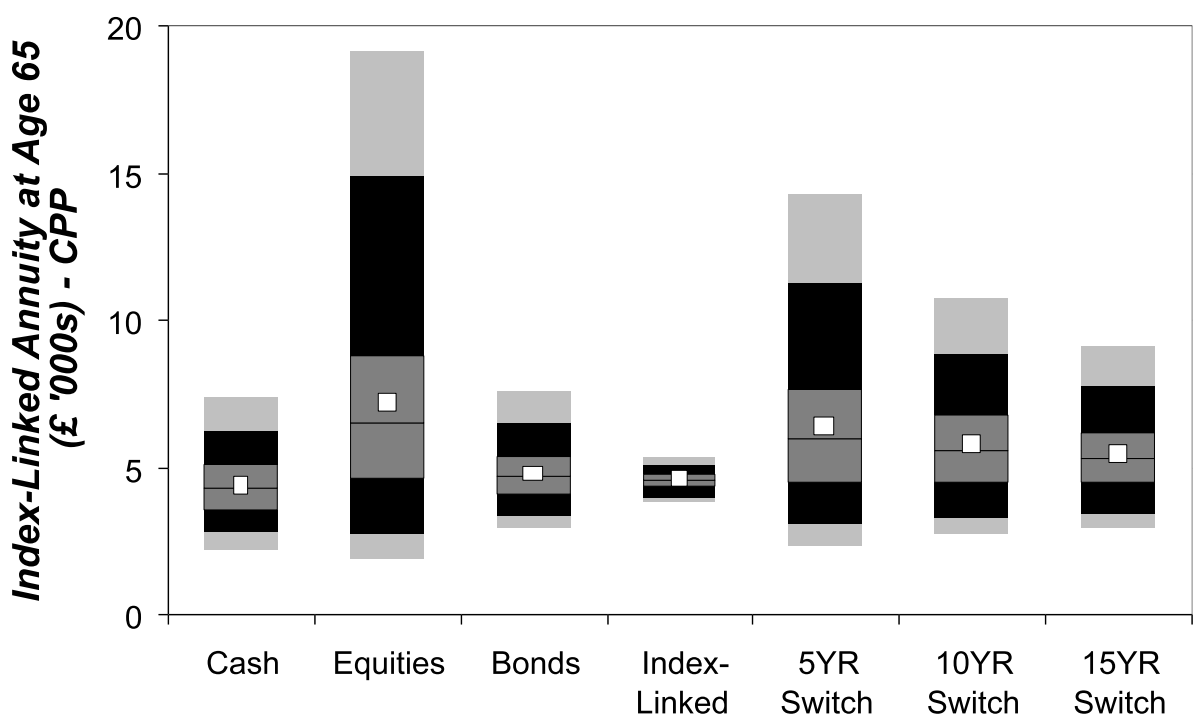

Figure 14: Distribution of index-linked annuity at age 65 (current purchasing power)

benefits, conventional bonds are risky because they do nothing to hedge against unexpected inflation.

Looking at Figure 14, someone might argue: 'Surely, it's obvious that $\mathrm{Mr}$ Gently should invest all his assets in equities — the 95th percentile outcome is not much worse than any other strategy and there is lots more upside. Anyway, who would hold index-linked bonds when there's at least a 70 per cent probability that you'll be better off in equities? Switching into conventional bonds just reduces benefits. It does not 
get rid of the much of the downside risk'. Now, notwithstanding the fact that equities do look worse in terms of a 95th percentile comparison and that nothing has been said about the saver's appetite for risk, this observation is fair. However, it is important to realise that Figure 14 only helps to analyse 'Question 1'. The benefits of Lifestyle switching strategies relate to 'Question 2', which concerns the build-up of benefits over the years approaching annuity purchase and the potential for benefit surprises. Let us now address that question.

\section{'Question 2' and benefit surprises}

Consider now the year-on-year change in the conventional annuity the fund could buy at age 65 for the various investment policies. In other words, compare the annuity achieved at age 65 with what could have been achieved one year earlier at age 64 . It is clear that, in these terms, an equity policy is dramatically more risky than a policy of holding a 15-year conventional bond. The 15-year bond is almost a perfect match for the (conventional) annuity, so almost all the interest rate risk has been removed. It can be seen that half the simulated outcomes at age 65 fall within plus or minus 1 per cent of the projected benefit one year earlier.

For equities, there is a 25 per cent probability that the annuity at age 65 could turn out to be 8 per cent or more lower than the projected level at age 64 as a result of falling equity prices and interest rates. It can be seen that the switching strategies damp down this risk to projected benefits in the final year of the plan. Since the bulk of the fund's assets are held in bonds this should not surprise us.

Now suppose the same analysis is made at age 63 , and compare the annuity rate to the projection at age 62 . The results are set out in Figure 16. Because the bond exposures of the three switched funds are now lower, the spreads are higher. Indeed, the five-year switch fund is still invested 40 per cent in equities, so the spread of the profile for the five-year switch fund displays about 40 per cent of the spread of the equity profile. Note also how the spread of results for cash and index-linked is slightly wider than at age 65. This result arises because at age 63, the liability (to buy a conventional annuity deferred for two years) is more volatile than at age 65 .

In Figures 15 and 16 the spread of outcomes associated with the bond policy look very similar. In reality, this hides a more complicated picture. Figure 17 shows the profile for each year over the ten-year savings horizon for $\mathrm{Mr}$ Gently. The previous two figures can be thought of as slices through Figure 17 at age 63 and 65 . It can be seen that the variation in the annuity rate falls until year nine then rises again. You might ask 'what is going on here?'. The answer relates to the difference in duration ${ }^{9}$ between the 15-year bond held in the asset portfolio and the duration of the deferred annuity. At year 2, the annuity has a longer duration and exhibits more volatility (for a given change in interest rates) than the bond. Rising interest rates will increase the projected benefit. By the time Mr Gently reaches 63, the duration of the 15-year bond and the liability match almost perfectly and the change in the benefit over year 8 falls within a very narrow range. At year 10, once again there is a duration mis-match, although at this point, the bond duration is greater than the liability so that rising rates will reduce projected benefits.

Note that risk is never completely eliminated because some residual mortality risk cannot be matched with a 'vanilla' bond investment. 


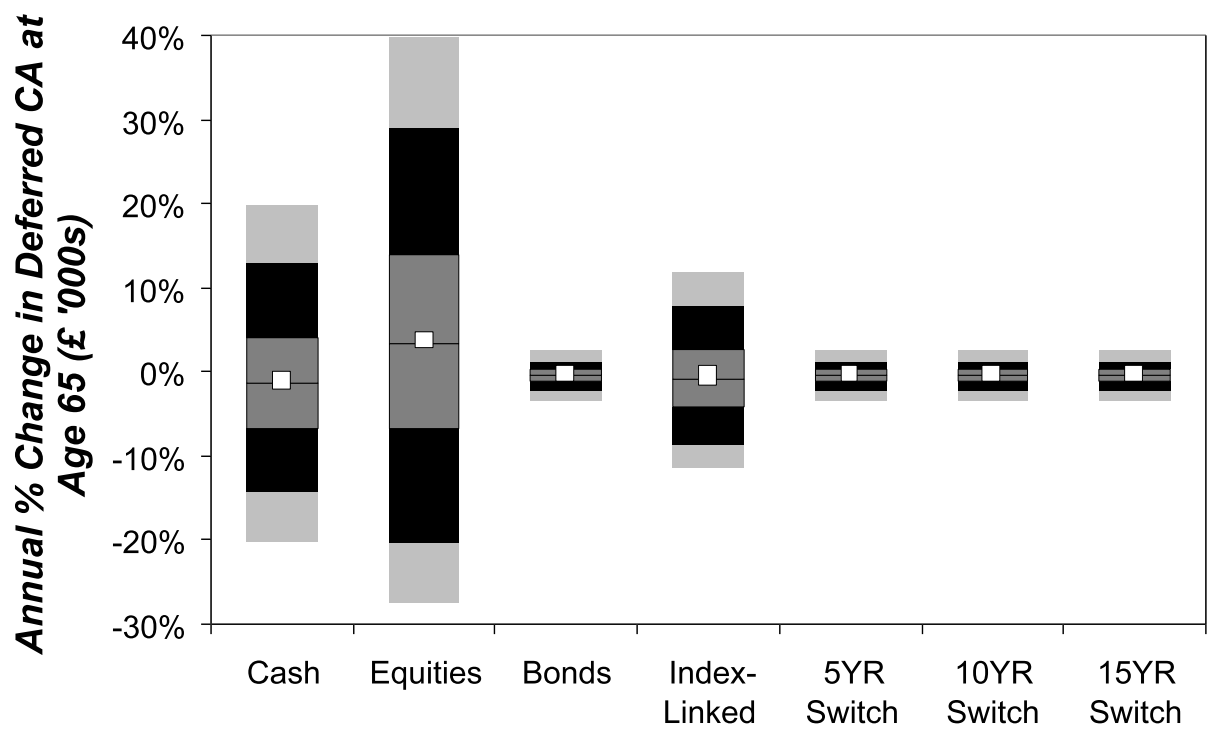

Figure 15: Distribution of year-on-year deferred conventional annuity change at age 65

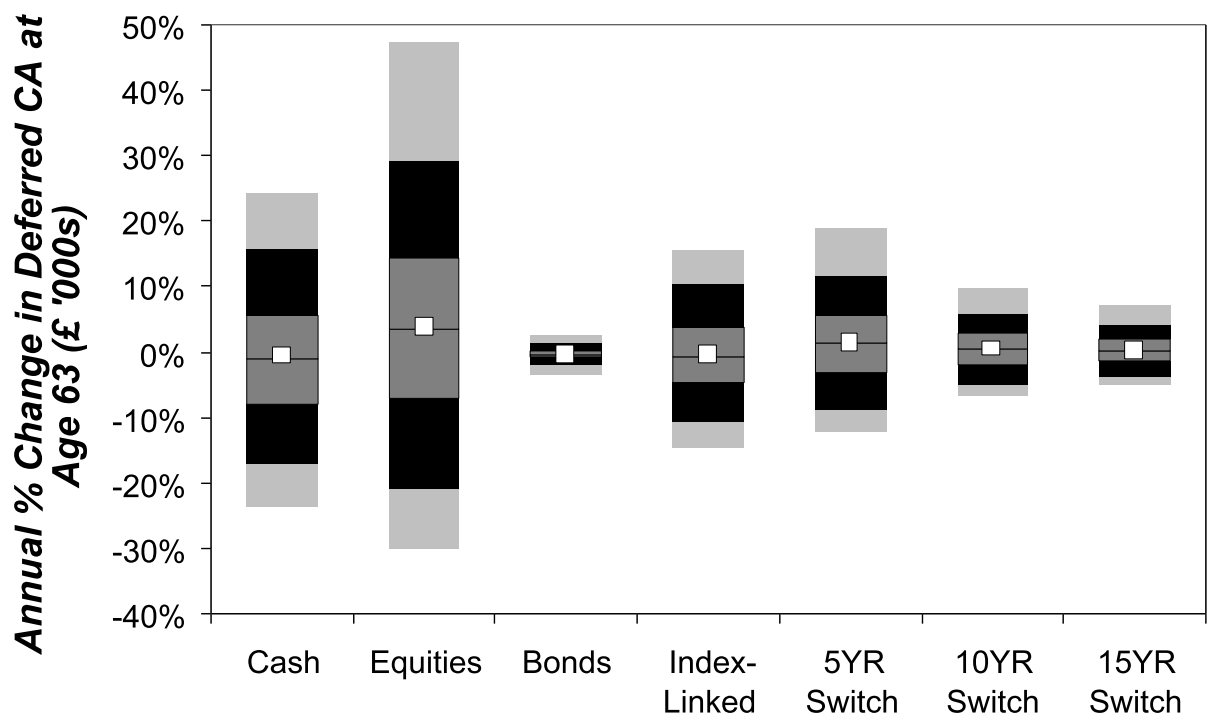

Figure 16: Distribution of year-on-year deferred conventional annuity change at age 63

\section{Summary and conclusions}

This paper is intended as a first step towards understanding the pensions 'lifestyle' problem and designing efficient solutions for savers. A stochastic simulation model has been used to map out the benefits likely to be delivered from some conventional investment policies and switching policies. Benefits in nominal and real terms have been analysed. Importantly we have differentiated between risks to the final benefits from a savings plan and the volatility of the build-up of benefits as a 


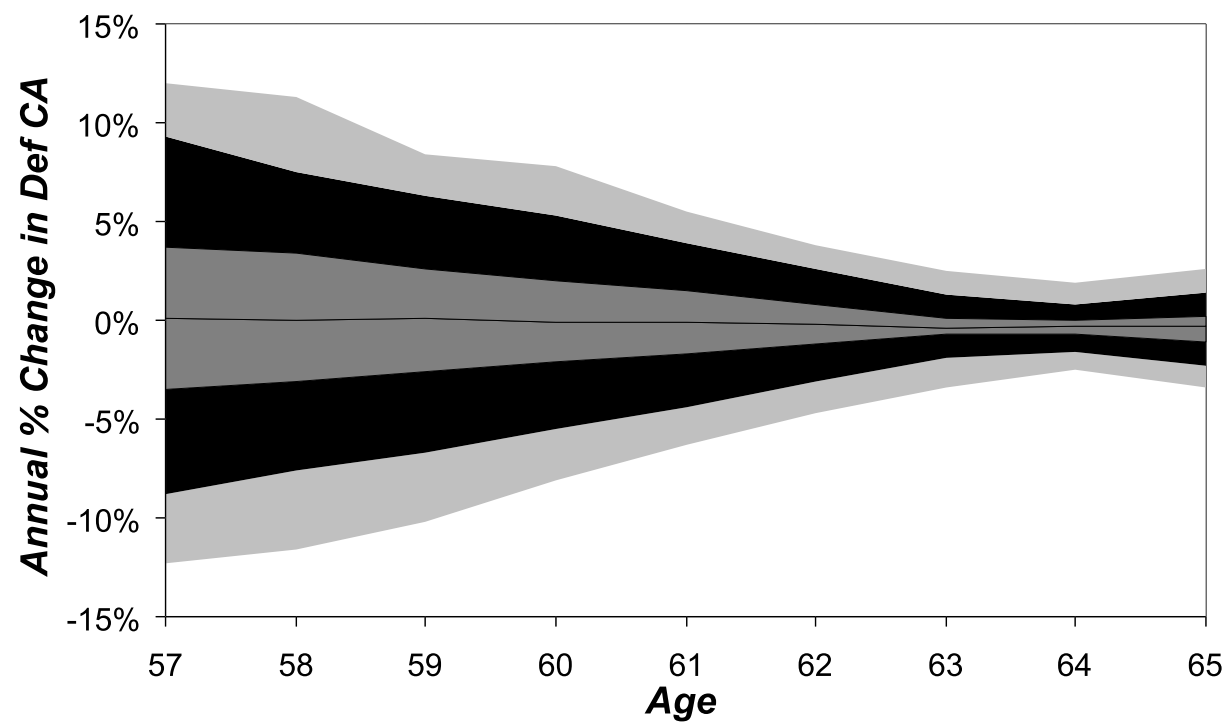

Figure 17: Distribution of year-on-year conventional annuity change for ages $57-65$ (100\% bonds)

plan approaches maturity. The analysis confirms that, for savers with long horizons, equities produce significantly better benefits than low-risk alternatives. Equity-based strategies are likely to outperform bond strategies at long horizons. However, the real problem with equity-based investment comes as the saver nears retirement. It has been demonstrated that for equity strategies, the year-on-year changes in projected benefits are potentially very large. This paper shows one partial solution - a switch to long bonds as the savings plan matures.

This paper will close with a final thought. It has analysed the potential variation in future benefits assuming a fixed contribution rate. But, suppose the problem was turned on its head. Just suppose that the saver does not set a fixed contribution rate. Instead, he targets a desired pension income and (just like a final-salary pension scheme) we re-set the contribution level from time to time in order to achieve that desired level of pension income. In this case it might be asked how volatile the required contribution rate might be over time. The saver would always get his target pension, but he may have to live with some large and volatile pension contributions (subject to his choice of investment policy of course).

Alternatively, the saver might choose to work (assuming he has that option) until he can fund a desired level of pension income. For some individual, this could mean working until age 67 rather than 60. In this case it could be asked what the distribution of retirement ages might look like (rather than the final benefit). The problem has been analysed from one rather conventional perspective, but in the future world of individual pensions people may need to question much of the accepted wisdom. Certainly, there are some other alternative perspectives which might be the focus for some interesting future analysis.

(C) Barrie \& Hibbert Limited

\section{References}

1 Where the periodic annuity payment is linked to changes in the retail price index so that the annuity maintains a constant level of 'purchasing power'. 
2 This property of the policy is sometimes referred to as 'build-up risk' or 'accumulation risk'.

3 The authors do recognise that, to some extent, all models are influenced by past experience. However, we expect a useful simulation model to show some patterns like the past as well as scenarios which may be unfamiliar, but which are quite plausible.

4 Hibbert, A. J., Mowbray, P. I. and Turnbull, C. J. (2001) 'A Stochastic Asset Model and Calibration for Long-Term Financial Planning Purposes', Barrie \& Hibbert research report \#57, Edinburgh, June.

5 A 'spot' interest rate for a given term is the zero-coupon yield for that term.

6 This is the return in excess of the 12-month interest rate.
7 ie the retail price index re-based to the beginning of the simulation.

8 In other words, using simulated interest rates, we calculate the annuity the accumulated fund would buy at age 55 , but starting at the planned retirement date.

9 Duration tells us about the sensitivity of bond prices to small yield changes. It is calculated by weighting the present value of each cash flow by its term. It gives a good estimate of the sensitivity of a stream of cash flows to yield changes so long as those changes are small and even across the yield curve. For large movements and 'twists' in the yield curve duration will become a poorer measure of matching performance. 